INVESTIGACIÓN PROCESO HISTORICO DE RECOBROS AL FOSYGA, TECNOLOGIAS DE SALUD NO CUBIERTAS POR EL PLAN OBLIGATORIO DE SALUD

OMAIRA ZAMORA

\author{
UNIVERSIDAD SANTO TOMÁS \\ FACULTAD DE ECONOMÍA \\ ESPECIALIZACIÓN EN AUDITORÍA EN SALUD \\ BOGOTA D.C \\ 2018
}




\section{INVESTIGACIÓN PROCESO HISTORICO DE RECOBROS AL FOSYGA, TECNOLOGIAS DE SALUD NO CUBIERTAS POR EL PLAN OBLIGATORIO DE SALUD}

OMAIRA ZAMORA

Trabajo de grado para optar al título de Especialistas en Auditoría en Salud

Docente Asesor

Dra. ALEJANDRA VALENZUELA CAZES

UNIVERSIDAD SANTO TOMÁS

FACULTAD DE ECONOMÍA

ESPECIALIZACIÓN EN AUDITORÍA EN SALUD

BOGOTA D.C

2018 
TABLA DE CONTENIDO

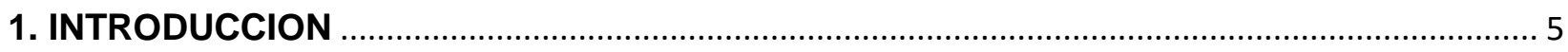

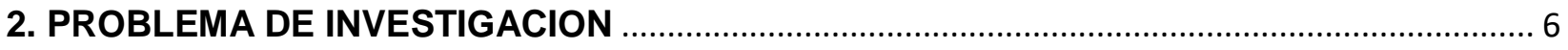

3. OBJETIVOS

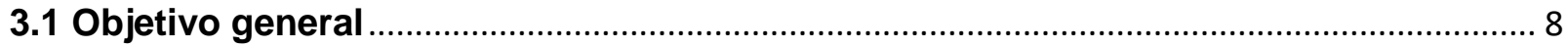

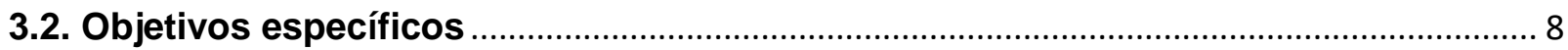

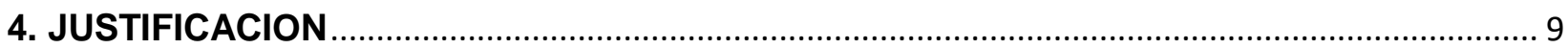

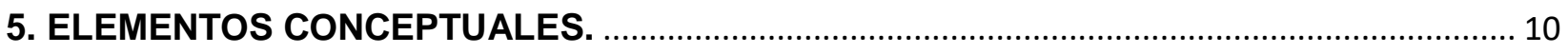

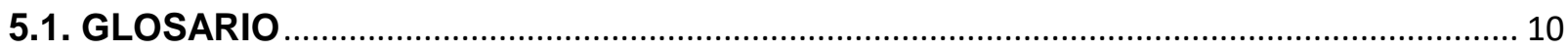

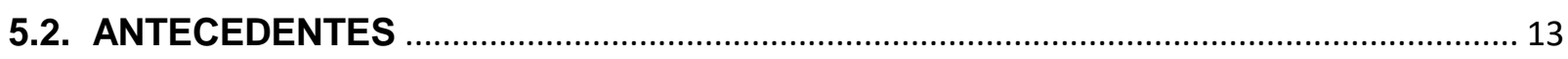

5.3. HISTORIA E RECOBROS ……………………………......................................... 135

5.4. EXPERIENCIA DE SISTEMAS DE SALUD EXTRANJERAS ………………….......... 138

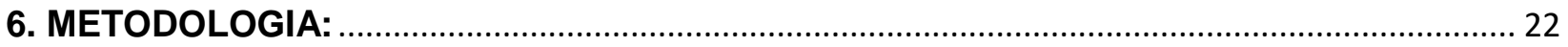

7. RESULTADOS:

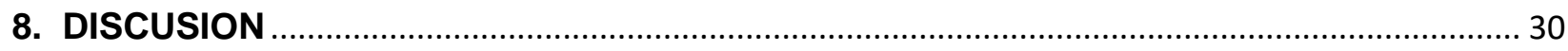

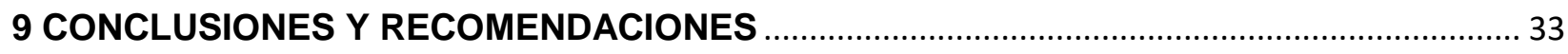

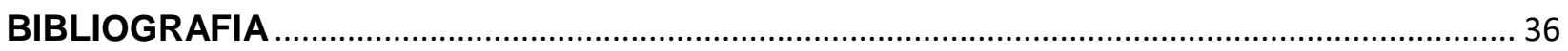




\section{RESUMEN}

El trabajo está dividido en capítulos como: antecedentes, contexto, metodología, discusión y conclusiones. La estructura de esos capítulos se explica a continuación:

El antecedente explica brevemente algunos rasgos de los sistemas de salud e inserta la prestación de servicios No POS dentro del Sistema colombiano.

El segundo capítulo trata de una investigación histórica de recobros por tecnologías No Pos desde su inicio y el aumento desmedido año tras año

El tercer capítulo describe brevemente la metodología para el hallazgo de resultados, indicando principalmente un estudio transversal que permitirá tener una línea de base para medir en posteriores estudios el impacto financiero causado por el desborde en los recobros al Fosyga por tecnologías No Pos y Finalmente, se proponen las conclusiones. 


\section{INTRODUCCION}

Los servicios de atención en salud no incluidos en el plan obligatorio de salud POS para los afiliados al régimen contributivo - $\mathrm{RC}$ del Sistema General de Seguridad Social en Salud - SGSSS denominados servicios NO POS son autorizados por el Comité Técnico Científico - CTC de una EPS o por fallos de Tutela, el reconocimiento y pago lo realiza el Fondo de Solidaridad y Garantía FOSYGA y están reglamentados mediante la resolución 5395 de 2013. (1)

El comportamiento acelerado de los recobros presentados al FOSYGA en los últimos años representaba una de las grandes amenazas para la sostenibilidad del SGSSS situación que género la estructuración e implementación de acciones de revisión y control de la política de reconocimiento y pago de estos servicios.(1)

Teniendo en cuenta el comportamiento de los recobros y el pronunciamiento de la Honorable Corte constitucional en particular la Sentencia T-760 de 2008, el Ministerio de Salud y Protección Social adelanto acciones con las cuales se ha logrado moderar la tendencia del valor recobrado y aprobado, que según los estimativos para la vigencia 2014 hubiera alcanzado el valor aprobado de 4 billones, mientras que al cierre de la misma el valor aprobado se estableció en 2.1 billones. (1)

Por lo anteriormente descrito el trabajo de grado brinda una investigación histórica en el proceso de recobros por tecnologías NO POS al Fosyga, sus cambios, las implicaciones del aumento desmedido de recobros años tras años para el sistema de salud 


\section{PROBLEMA DE INVESTIGACION - AUMENTO DESMEDIDO DE RECOBROS AL FOSYGA}

La Procuraduría General de la Nación y la Pontificia Universidad Javeriana -Centro de Proyectos para el Desarrollo (Cendex)-presentaron una investigación sobre el comportamiento e impacto de los recobros de medicamentos y procedimientos al Fondo del Sistema General de Seguridad Social en Salud (Fosyga). (2)

De acuerdo con la entidad "los recobros al Fosyga pasaron de 200.000 millones de pesos en el 2005 a 2,3 billones en el 2010, comportamiento que amenaza la estabilidad financiera del Sistema de Salud" (2).

La sostenibilidad financiera del Sistema ha sido un tema recurrente como titular de prensa en Colombia que alerta sobre la amenaza causada por los altos recobros que se generan debido a la prestación de servicios No POS. Han sido las entidades públicas como la Defensoría del Pueblo (2012) y la Procuraduría General de la Nación (2012) las que han mostrado cifras que, aunque generales, son el punto de partida para que se genere el debate en torno a los costos de los servicios no contemplados en el plan de beneficios y recobrados billonariamente por las EPS.

El proceso de recobros al FOSYGA por tecnologías de salud no cubiertas por el Plan Obligatorio de Salud se inició en los años de 1997 desde entonces se ha incrementado año tras año. De Los años 1997 a 2000 el total de recobros fue de Col\$ 4.244.000.000.(acumulado de 4 años). En el año 2001 en un solo año los recobros llegaron a Col\$ 5.311.000.000. El año 2002 llegó a Col\$ 56.741.000.000, es decir, prácticamente se multiplicaron por 10. En el año 2003, los recobros ascendieron a Col\$113.708.999.000. Es decir, un poco más del doble. Los valores recobrados al FOSYGA llegaron a Col\$ 291.606.000.000. El año 2006 los valores recobrados al FOSYGA llegaron a Col\$ 628.254.000.000. El año 2007 los recobros al FOSYGA superaron la barrera del Billón; Llegaron a Col $\$ 1.018 .762 .000 .000$. El año 2008 los valores recobrados al FOSYGA llegaron a Col\$1.150.114.000.000. En el año 2010, se estima que los valores recobrados al FOSYGA pueden llegar a Col\$1.500.000.000.000. (3) 
El año 2009 subieron a $\$ 1,9$ billones en el régimen contributivo y a cerca de $\$ 2$ billones en el subsidiado. Reclamó al gobierno precios razonables para los recobros, al constatar abusos en este punto. Según cálculos de la Contraloría General de la República, cumplir la Sentencia T-760 cuesta cerca de $\$ 6$ billones al año, concluyó el Contralor. (3)

Revisado el informe de la Defensoría del Pueblo (2012) sobre la tutela y el derecho a la salud, se encuentra que en 2011 fueron interpuestas 105.947 tutelas por colombianos que sintieron vulnerados sus derechos en salud, que corresponden al $26.14 \%$ del total de las acciones invocadas en ese año (405.359). De las 105.947 tutelas, el 32.19\% estaban relacionadas con solicitudes de servicios o medicamentos no incluidos en el Plan Obligatorio de Salud (Colombia. Defensoría del Pueblo, 2012). (3)

El 82.5\% de los procedimientos no POS, según la base de datos de recobros del Fosyga, fueron autorizados a través del Comité Técnico Científico de las diferentes EPS, mientras el 17.5\% fue autorizado a través del mecanismo de acción de tutela. Un número importante de usuarios del sistema acudió a la acción constitucional para obtener la prestación de un servicio de salud, que además de derecho, tiene un procedimiento preestablecido para el trámite, como es la solicitud ante el Comité Técnico Científico de la Entidad Promotora de Salud. (3) 


\section{OBJETIVOS}

\subsection{Objetivo general}

Realizar una revisión histórica sobre los recobros por tecnologías NO POS al FOSYGA con el fin de realizar un análisis de identificación de posibles errores en el aumento desmedido de recobros al FOSYGA

\subsection{Objetivos específicos}

- Identificar la normatividad que regula los recobros al FOSYGA a lo largo de tiempo.

- Describir la implicación económica y financiera de los recobros en el sistema de salud.

Describir la problemática de los posibles errores por parte de la EPS en cuanto a exclusiones del POS. 


\section{JUSTIFICACION}

Esta investigación histórica de recobros de tecnologías No Pos, tiene como objetivo el analizar el aumento de los recobros al fosyga que genera un impacto financiero el cual conlleva una desestabilidad económica tanto del estado como de las EPS e IPS. Ante la evidencia de este comportamiento que amenaza la estabilidad financiera del Sistema de Salud, el informe conocido por Colprensa estima que la forma de definir los medicamentos en el NO POS debería pasar de las concentraciones y las vías de administración, a los principios activos, para así generar una disminución importante de los recobros.(4)

Mantener el equilibrio económico del sistema de salud, asegurando que las decisiones del CTC O FALLO DE TUTELA, autoricen únicamente la prestación de aquellos servicios de salud que son necesarios y justificados desde una perspectiva técnico-científica, de modo que los recursos del sistema destinados al cuidado de la salud individual no se diluyan en la prestación de servicios superfluos, ineficaces, sub óptimos o innecesarios, sino que se inviertan en su verdadera finalidad, que es cuidar la salud de los individuos en todas sus dimensiones. La necesidad de cambiar la forma como se definen los medicamentos y los procedimientos del Plan Obligatorio de Salud, POS, es una de las principales conclusiones que se derivan de una investigación realizada por la Procuraduría y la Universidad Javeriana sobre los recobros que se hicieron al Sistema General de Seguridad Social en Salud entre el 2006 y 2012. (4)

La investigación afirma que los recobros por procedimientos y medicamentos al Fondo del Sistema General de Seguridad Social en Salud (Fosyga), cuyo principio activo sí está en el POS, pasaron de los $\$ 200.000$ millones en el 2005 a $\$ 3,1$ billones en el 2010.(4). 


\section{ELEMENTOS CONCEPTUALES.}

\subsection{GLOSARIO}

5.1.1. Beneficiario: persona cubierta por el seguro de salud de un familiar

5.1.2. Capitación: modalidad de contratación en la cual se pagan por anticipado un número de servicios.

5.1.3. Código De Procedimientos: un sistema de codificación utilizado para describir los Tratamientos realizados.

5.1.4. Copago: cuota que paga el usuario del régimen subsidiado para ayudar a financiar el sistema

5.1.5. Cuota Moderadora: valor que debe pagar el usuario por una atención a su EPS.

5.1.6. CUPS: código único de procedimientos en salud

5.1.7. Diagnóstico: código que se utiliza para la facturación y que describe su enfermedad.

5.1.8. EAPB: entidades administradoras de planes de beneficios permitidos en el SGSSS.

5.1.9. EPS: empresas promotoras de salud

5.1.10. EPS-S: empresas promotoras de salud subsidiada

5.1.11. ESE: empresas sociales del estado.

5.1.12. FOSYGA: fondo de solidaridad y garantía

5.1.13. Glosa: No conformidad que afecta en forma parcial o total el valor de la factura por prestación de servicios de salud, encontrada por la entidad responsable del pago, durante la revisión integral que requiere ser resuelta por parte de prestador de servicios de salud. (Resolución 3047/ 2008.

5.1.14. FACTURA: Documento que representa el soporte legal de cobro de un prestador de servicios de salud a la entidad responsable de pago de servicios de salud por venta de servicios prestados, que debe cumplir los requerimientos exigidos por la DIAN. (Resolución 3047/ 2008. 
5.1.15. AUDITORÍA DE CUENTAS MÉDICAS: proceso mediante el cual se verifica la conformidad de los valores y soportes que conforman la facturación presentada por las diferentes Instituciones Prestadoras de Salud (IPS), frente a parámetros previa.

5.1.16. Auditoría integral: es la etapa en la cual se verifica el cumplimiento de los requisitos esenciales para el pago de los recobros, teniendo en cuenta los ámbitos técnico-médico, jurídico y financiero.

5.1.17. IPS: institución prestadora de servicios de salud

5.1.18. Mapipos: manual de intervenciones y procedimientos

5.1.19. Número De Historia Clínica: el número asignado por IPS que identifica su historia clínica individual.

5.1.20. Plan De Beneficios: actividades procedimientos e intervenciones que cubre el asegurador POS, POS-S

5.1.21. Red De Servicios: IPS contratadas por el asegurador para garantizar la atención de salud.

5.1.22. Responsable de Pago: la(s) persona(s) responsable de pagar su factura se le denomina garante.

5.1.23. Servicios no Cubiertos: cargos por servicios médicos denegados o excluidos por su seguro.

5.1.24. SOAT: seguro obligatorio de accidentes de tránsito

5.1.25. UPC: unidad de pago por capitación

5.1.26. UPS-S: unidad de pago por capitación subsidiada

5.1.27. Vinculado: persona que no tiene seguridad social

5.1.28. Recobro: Solicitud de reembolso, presentada por una Entidad Administradora de Planes de Beneficios, tendiente a obtener el reconocimiento y pago de los servicios médicos y/o los medicamentos no incluidos en el Plan Obligatorio de Salud prestados a los afiliados y/o beneficiarios de dichas entidades, de acuerdo con lo establecido en la normatividad vigente.

5.1.29. Recobro por tecnologías en salud no pos: Es aquel presentado por la Entidad Administradora de Planes de Beneficios, por actividades, intervenciones, insumos, medicamentos, dispositivos, servicios y procedimientos no incluidos en el Acuerdo 029 de 2011 que define, aclara y actualiza integralmente el Plan Obligatorio de Salud y demás 
normas que lo modifiquen o adicionen de acuerdo con lo establecido en la normatividad vigente. Se presenta en los formatos MYT-R, MYT-R - Anexo 1 y MYT-01.

5.1.30. Recobro por Fallos de Tutela: Es aquel presentado por la Entidad Administradora de Planes de Beneficios, en cumplimiento de lo ordenado por un Juez de la República mediante Fallo de Tutela, obedeciendo a tecnologías en salud no incluidas en el Plan Obligatorio de Salud. Se presenta en los formatos MYT-R, MYT-R - Anexo 1 y MYT-02.

5.1.31. Recobro rechazado: Es aquel recobro que se rechaza de manera definitiva a la entidad reclamante y que no puede volver a ser presentado por ésta. Resolución 3099 de 2008.

5.1.32. Recobro devuelto: Es aquel recobro que se devuelve a la entidad recobrante para que subsane la(s) inconsistencia(s) que se encontraron en la auditoría y se vuelva a presentar nuevamente al administrador fiduciario Art. 16 Resolución 2933 de 2006 y Resolución 3099 de 2008.

5.1.33. Recobro con aprobación condicionada: Es aquel recobro que incurre en una de las causales de aprobación condicionada definidas en el artículo 17 de la Resolución 2933 de 2006 y Resolución 3099 de 2008. La documentación que completa o actualiza el recobro con estado aprobado condicionado se remite en el formato MYT-03.

5.1.34. Recobro aprobado para pago: Es aquel recobro que cumple con todos los requisitos que exigen las normas legales vigentes, y por lo tanto su pago es aprobado Art. 13 Resolución 2933 de 2007 y Resolución 3099 de 2008.

5.1.35. Recobro con reliquidación: Es aquel recobro con pago por un valor diferente al solicitado, por incurrir en las causales definidas en el artículo 18 de la Resolución 2933 de 2006 y Resolución 3099 de 2008.

5.1.36. Causales de objeción para rechazo, devolución o aprobación condicionada: Objeción al pago de un recobro por incumplimiento de un requisito para su aprobación (5) 


\subsection{ANTECEDENTES}

La salud en Colombia se presta bajo un modelo de aseguramiento, cuyo principal propósito es brindar al Sistema un soporte financiero sostenible en el tiempo, permitiéndole el acceso a los servicios a amplios sectores de la población, con dirección a la universalización. Se propone un esquema, a través del cual, las funciones de manejo del riesgo en salud y de la administración de la prestación de los servicios de salud, queda en manos de las Entidades Promotoras de Salud que pueden ser públicas, privadas o comunitarias. Estas aseguradoras deben garantizar a todos los afiliados, a través de un pago capitado denominado Unidad de Pago por Capitación (UPC), la prestación completa del plan de beneficios ordenado por la Ley (Colombia. Congreso de la República, 1993).(15). El esquema financiero del Sistema contempla para su operación la existencia de dos regímenes: el contributivo y el subsidiado. El Régimen Contributivo está integrado por aquellas personas con capacidad de pago, quienes deben aportar el $12,5 \%$ de sus ingresos, y que en caso de generarse excedentes, se destinan a completar los recursos necesarios para la afiliación a este régimen, de aquellos cuyo aporte es insuficiente para pagar las UPCs, a través de la figura denominada compensación. Del Régimen Subsidiado hacen parte las personas sin capacidad de pago y se financia con un punto que traslada el Régimen Contributivo y con aportes fiscales, esfuerzo propio de las entidades territoriales y rentas cedidas (Colombia. Congreso de la República, 2007). (16).

La afiliación al Sistema de Salud da derecho al otorgamiento de un paquete de beneficios básicos que comprende servicios, procedimientos e insumos (incluyendo medicamentos) en todas las fases de la relación salud-enfermedad (promoción, prevención, tratamiento y rehabilitación) y en todos los niveles de complejidad. Su contenido, tanto a nivel de procedimientos y servicios como de medicamentos, debe ser revisado y ajustado periódicamente por la Comisión de Regulación en Salud, teniendo en cuenta el cruce de características de la carga de la enfermedad en el país, con análisis de costos y efectividad de las intervenciones disponibles (Colombia. Congreso de la República, 2007).(16). Ese Plan de Beneficios al que tienen derecho todos los afiliados al Sistema de Salud en Colombia es finito, y la limitación de las prestaciones y servicios 
contemplados obedece a procesos de priorización, necesarios para asegurar el equilibrio financiero del Sistema.

Su definición debe estar enfocada en las coberturas de las necesidades de salud más relevantes para el país y en la asignación eficiente de los recursos escasos que están disponibles (Aldea, 2009, citado por Castrillón, 2009).20 Al igual que en Colombia, la búsqueda de una mayor eficiencia del gasto público en salud, fue uno de los objetivos centrales de las reformas en salud de otros países, tal es el caso de Israel, Chile, Oregón -EEUU, Nueva Zelanda, México y Holanda, que buscaron el establecimiento de una canasta única con un número limitado de prestaciones (Ariza, Giedion, \& Pulido, 2007).(21). Pese a que en Colombia se predique la existencia de un Plan Obligatorio de Salud limitado, el diseño estructural del sistema está transversalizado por el principio de solidaridad y permite a través del Fondo de Solidaridad y Garantía -Fosyga- garantizar la prestación de tecnologías excluidas del POS, luego de que el Comité Técnico Científico de cada EPS conceptúe sobre su necesidad. De igual manera, la intervención activista de las Altas Cortes, especialmente la Constitucional, ha favorecido la prestación de servicios excluidos, contrario a lo que sucede en países como Estados Unidos e Israel, que definieron un conjunto de servicios al cual la gente puede acceder única y exclusivamente, sin que se preste otro servicio que allí no esté contemplado (Ariza et al., 2007). La jurisprudencia constitucional en Colombia ha señalado que: Frente a las limitaciones del sistema de salud, los individuos son los primeros convocados a proveerse aquellos servicios médicos que se encuentran excluidos de la cobertura del POS y que, solo en aquellos casos en que carezcan de recursos económicos suficientes para tal fin, procede la intervención del Estado (Colombia. Corte Constitucional, 2006).(17).

Ahora, esa responsabilidad subsidiaria del Estado señalada por la Corte, pareciera ser principal y así lo demuestran los abundantes fallos de tutela a través de los cuales la corporación ha señalado que: Como desarrollo del principio de supremacía de la Constitución, consagrado en el artículo 4 superior, resulta procedente la acción de tutela para ordenar el suministro de medicamentos o tratamientos médicos que no se encuentran incluidos en el POS y que sean indispensables para garantizar la vida en 
condiciones dignas u otros derechos fundamentales, cuando el afiliado carezca de recursos económicos suficientes para sufragarlos (Colombia. Corte Constitucional, 2009). (18). Esa protección jurisdiccional, aunada a los incentivos perversos de los distintos agentes que tienen alguna relación con los Comités Técnico Científicos de las EPS (CTC), amenaza con agudizar el grave problema de financiación del Sistema de Salud en Colombia, procurando autorizaciones abundantes de tecnologías excluidas del POS, que luego serían recobradas al Fosyga. Esta situación pudiera ser controlada bajo el nuevo esquema para el trámite de procedimientos No POS, planteado por la Ley 1438 de 2011, que reestructura la conformación de los CTC y crea la Junta Técnico Científica de Pares adscrita a la Superintendencia Nacional de Salud (Colombia. Congreso de la República, 2011). (19). En tanto que centralizaría en un ente de control la decisión de autorizar o no servicios excluidos del plan de beneficios, tomada a la luz de criterios técnicos que deberán ser observados por expertos pares de quienes ordenaron tal tecnología.

\subsection{HISTORIA DE RECOBROS.}

El año 2001 en un solo año los recobros llegaron a Col\$ 5.311.000.000. El año 2002 llegaron a Col\$56.741.000.000, es decir, prácticamente se multiplicaron por 10. Como respuesta, al finalizar ese año, la Comisión Nacional de Precios de Medicamentos, liderada por el entonces Ministro de Salud y Trabajo, Dr. Juan Luis Londoño Cuesta, expidió la Circular 04 de 2002 que elevó a 132 los medicamentos sometidos al régimen de "control directo" (máximo nivel de regulación) y llevó más de 1.000 productos de 32 laboratorios al régimen de "libertad regulada", por incrementos de precios excesivos e injustificados y/o incumplir con la obligación de reportar sus precios a la CNPM. El año 2003, los recobros ascendieron a Col\$113.708.999.000. Es decir, un poco más del doble. Se expidió la Circular única de 2003 que introdujo algunas modificaciones a las Circulares 4 y 5 de 2002.(3)

La profundización de la política de des regulación de precios de medicamentos comenzó realmente con la Circular 01 de 2004 que pasó varios medicamentos de cáncer 
(oncológicos) a régimen de "libertad regulada" en lugar de régimen de "control directo" que les correspondía por tratarse de medicamentos con menos de 3 oferentes en el mercado, ("monopólicos", que pueden abusar de su posición dominante en el mercado).

El año 2005 ante el XII Foro Farmacéutico de la Asociación Nacional de Empresarios de Colombia AND, se presentó el "Estudio de la Política de Precios de Medicamentos en Colombia" realizado por la firma "Econometría" y financiado por AFIDRO y ASINFAR (gremios de farmacéutica multinacionales y nacionales) que pone las bases para una mayor liberalización de precios. Ese año, los valores recobrados al FOSYGA llegaron a Col\$291.606.000.000. El año 2006 la CNPM publicó la Circular 04 de 2006 que con base en el estudio de Econometría eliminó el régimen de "control directo automático" que regía para los precios de medicamentos con menos de 3 oferentes en el mercado. El año 2006 los valores recobrados al FOSYGA llegaron a Col\$628.254.000.000. El año 2007 todos los medicamentos en Colombia estaban en régimen de "libertad vigilada" es decir, solo con la obligación de reportar sus precios al Sistema de Información de Medicamentos SISMED del Ministerio de la Protección Social. Ese año no se produjo ninguna decisión de regulación de precios por parte de la CNPM y los recobros al FOSYGA superaron la barrera del Billón; Llegaron a Col\$1.018.762.000.000.(3)

El año 2008 los valores recobrados al FOSYGA llegaron a Col\$1.150.114.000.000. y la Comisión Nacional de Precios de Medicamentos produjo 2 Circulares que llevaron solo 10 medicamentos a régimen de "libertad regulada". Ningún producto pasó al régimen de "control directo" de precios. En el año 2010, se estima que los valores recobrados al FOSYGA pueden llegar a Col\$1.500.000.000.000. y la Academia Nacional de Medicina y Federación Médica Colombiana advirtieron en su primera reunión con la Comisión de Regulación en Salud CRES que a este paso el sistema de salud avanza inexorablemente hacia el colapso financiero. (3)

El año 2009 subieron a $\$ 1,9$ billones en el régimen contributivo y a cerca de $\$ 2$ billones en el subsidiado. Reclamó al gobierno precios razonables para los recobros, al constatar 
abusos en este punto. Según cálculos de la Contraloría General de la República, cumplir la Sentencia T-760 cuesta cerca de $\$ 6$ billones al año, concluyó el Contralor.

Las EPS en Colombia únicamente están obligadas a garantizar los medicamentos, procedimientos e intervenciones estipuladas en el POS. Sin embargo, por vía de tutela comenzaron a autorizarse servicios y medicamentos excluidos del POS con cargo al Fosyga, en casos de urgencia y necesidad. Ante esta situación, surgen los CTC para controlar las autorizaciones de servicios no POS. Posteriormente, la figura de los recobros comenzó a ser utilizada indebidamente, lo cual ha traído como consecuencia el desequilibrio financiero del sistema; el mal uso ha llegado a tal punto, que se presentan solicitudes para obtener el pago de procedimientos, medicamentos e intervenciones que hacen parte POS o que pueden ser sustituidas por servicios e insumos que sí hacen parte del POS o con fines estéticos. La Defensoría del Pueblo (2012) indica que fueron interpuestas 105.947 tutelas por colombianos que sintieron vulnerados sus derechos en salud. Si se compara con el mismo dato de los últimos años, en 2011 se agudizó la problemática, acercándose a los niveles más altos registrados en 2007 y 2008 . El 67,81\% de lo solicitado a las EPS estaba incluido en el Plan Obligatorio de Salud (POS). (4)

La principal causa del crecimiento sostenido de las obligaciones por concepto de los eventos No POS se halla en los incentivos de los distintos agentes que tienen alguna relación con los planes de beneficios, entre los que se encuentran las aseguradoras, médicos tratantes, compañías farmacéuticas y usuarios. Ese crecimiento desmedido a partir de 2008 se debe, básicamente, a la ocurrencia de dos eventos que en nada tienen que ver con la alteración del perfil epidemiológico de los colombianos. El primero está relacionado con el pronunciamiento de la Corte Constitucional en sentencia de constitucionalidad y el segundo con la entrada en vigencia de una resolución expedida por el Ministerio de la Protección Social que modifica los porcentajes de recobros según sean tramitados por CTC o autorizados por tutela. En lo que refiere al primer evento, la Corte Constitucional (2008a), a través de la Sentencia C-463 se pronunció sobre la constitucionalidad del literal j) de la Ley 1122 (Colombia. Congreso de la República, 2007). En el segundo evento, el Ministerio de la Protección Social (2008) expidió el 2 de 
octubre la Resolución 3754 que modifica parcialmente la Resolución 3099 (Colombia. Ministerio de la Protección Social, 2008a). En Dicha norma se indica que los eventos que sean rechazados por los CTC y reconocidos por vía de tutela sólo podrían ser recobrados en un $85 \%$, lo que motivó a que las EPS se desbordaran en número de prescripciones y que los Comités autorizaran, sin hacer una evaluación objetiva y técnica de las solicitudes, eventos excluidos del POS. Estos efectos fueron los mismos que se presentaron con el fallo de constitucionalidad que amplió los eventos No POS que podían ser solicitados y recobrados e incentivó a que las EPS autorizaran a través de los CTC toda solicitud a fin de que se les reconociera el $100 \%$. por lo tanto el número de recobros por vía de los CTC superó al de tutelas a partir de 2008.(4).

En el intento de resolver o mitigar los problemas que atentan contra la estabilidad financiera del Sistema de Salud, el Gobierno Nacional adoptó una serie de medidas que incluyen, el control de precios de algunos de los medicamentos más recobrados a través del establecimiento de valores máximos de recobro (Colombia. Ministerio de la Protección Social, 2011).(22). El fortalecimiento de la función de inspección y vigilancia y control, de la función jurisdiccional y del defensor del usuario de la Superintendencia Nacional de Salud (Colombia. Congreso de la República, 2007) la creación del Instituto de Evaluación Tecnológica en Salud (IETS) (Colombia. Congreso de la República, 2007) y la reforma del Comité Técnico Científico (CTC) de las EPS y la creación de la Junta TécnicoCientífica de Pares. De las cuatro medidas, solo dos han entrado en funcionamiento, y cuyos logros han arrojado un ahorro o disminución en el gasto por recobro de medicamentos equivalente a 112 mil millones de pesos aproximados en 2011 (Colombia. Ministerio de la Protección Social, 2011). Las otras dos medidas son de carácter estructural que no han sido reglamentadas y menos implementadas. (22).

\subsection{EXPERIENCIAS DE SISTEMA DE SALUD EXTRANJERAS EN RELACIÓN A TECNOLOGIAS O SERVICIOS EXCLUIDOS EN EL POS}

Muchos países han adoptado paquetes básicos a lo largo de las últimas dos décadas que explicitan los servicios a que pueden acceder los afiliados o usuarios del sistema (Sojo, 
2006, citado por Giedion, Panopoulou, \& Gómez-Fraga, 2009).(23). Para Giedion et al. (2009) ninguna sociedad está hoy en día en capacidad de cubrir a "todos con todo", por lo cual es atendible la brecha existente entre lo "posible y lo factible". Sin embargo, la evidencia también permite ver que algunos Estados reconocen tecnologías que no fueron contempladas dentro de sus planes obligatorios. Parece haber consenso en que los criterios de costo efectividad, impacto sobre la calidad de vida e impacto sobre la esperanza de vida, juegan un papel preponderante al momento de priorizar los servicios de salud. (9)

Este proceso de priorización podrá darse a través de racionamientos explícitos o racionamientos implícitos (Cubillos, 2013) en el primero se define un plan de beneficios explícitos que niega rotundamente la prestación de servicios que no estén incluidos, y que por tanto deberán ser cubiertos por el paciente que los requiera. En el segundo se define una canasta básica con la posibilidad de acceder a otros servicios, previa revisión de un comité u órgano especializado. (12)

En Estados Unidos, por ejemplo, un alto porcentaje de su población no cuenta con ningún sistema de seguro médico. El $70 \%$ de los cubiertos se encuentra afiliado a aseguradoras privadas, y la prima es pagada con aportes conjuntos del empleador y del empleado. El resto de la población afiliada, ancianos, pobres y niños están adscritos al Medicare, Medicaid o SCHIP, programas públicos proveídos por el gobierno federal (United States of America. Center for Medicare \& Medicaid Services, 2011).(13)

México también adoptó, con base en la carga de la enfermedad y tomando en cuenta consideraciones de costo-efectividad, la creación de tres paquetes: de salud pública, de servicios esenciales de salud y de servicios de alta complejidad. (Giedion et al., 2009).(9)

En cuanto a priorización implícita, Nueva Zelanda puede ser un buen ejemplo. En vez de establecer un paquete de beneficios para todos los neozelandeses con recursos públicos (nivel macro), concentró los esfuerzos de priorización en casos particulares (Giedion, 2008). La tendencia internacional a establecer paquetes básicos de servicios de salud, 
son claro ejemplo de la búsqueda de una mayor eficiencia del gasto público, a partir de procesos de priorización. (8)

El sistema de salud de Israel es, posiblemente, el que más se asemeja al sistema colombiano en el ámbito internacional y el que también puede aportar, dada su similitud, importantes lecciones en el caso de la priorización (Giedion, 2008). (8)

Chile optó por definir el contenido de su canasta de servicios en términos de patologías cubiertas, guías clínicas asociadas a éstas y garantías explícitas de calidad, oportunidad y protección financiera (Becerril-Montekio, Reyes, \& Manuel, 2011). El punto de partida para la priorización, según Giedion (2008), fue el análisis de la información del estado de salud de la población chilena en términos de morbilidad y mortalidad. (6)

El caso colombiano ilustra el anterior escenario, por cuanto a pesar de las restricciones del Plan de Beneficios del Sistema de Salud, se le reconoce a los afiliados, tecnologías y procedimientos excluidos, ordenando su pago contra los recursos del sistema en forma de recobros. Si se trata de afiliados al régimen contributivo que requieren de servicios excluidos del plan de beneficios, la prestación será con cargo a la subcuenta de compensación del Fondo de Solidaridad y Garantía Fosyga, en el caso del Régimen Subsidiado, se cargarán a las cuentas de las entidades territoriales.

En Colombia, la actualización del Plan Obligatorio de Salud es el resultado de una asignación prioritaria, por cuanto desde sus bases legales y técnicas se define como el conjunto de tecnologías en salud descritas en la Resolución 5521 de 2013 , que determina a qué tiene derecho, en caso de necesitarlo, todo afiliado al Sistema General de Seguridad Social en Salud -SGSSS, Se constituye en un instrumento para que las Entidades Promotoras de Salud EPS, garanticen el acceso a las tecnologías en salud. EI POS se articula con otros Planes de Beneficios del Sistema General de Seguridad Social en Salud SGSSS, así como con los programas, planes y acciones de otros sectores, que deben garantizar los demás aspectos que inciden en la salud y el bienestar (Colombia. Ministerio de Salud y Protección Social, 2013).(24). De igual modo, se previó 
que dicho plan pudiera actualizarse conforme lo señala el artículo $25^{\circ}$ de la Ley 1438 que estableció que el Plan de Beneficios deberá actualizarse integralmente una vez cada dos (2) años atendiendo a cambios en el perfil epidemiológico y carga de la enfermedad de la población, disponibilidad de recursos, equilibrio y medicamentos extraordinarios no explícitos dentro del Plan de Beneficios (Colombia. Congreso de la República, 2011). La sentencia T-760 (Colombia. Corte Constitucional, 2008b).(11)

En distintos países como Colombia, Argentina, Brasil y Costa Rica, la rama judicial ha ejercido un poder creciente sobre los servicios que tienen que ser financiados por los Sistemas de Salud (Giedion et al., 2009), (9). Haciendo notoria la tendencia latinoamericana de concebir la salud y sus servicios dentro de un enfoque de derechos. El encarecimiento del costo de la Salud en Colombia obedece, en gran medida, a fallos de tutela proferidos por las distintas Cortes, especialmente la Constitucional, que con argumentos de necesidad otorgan servicios no cubiertos por el plan básico. En estos casos la tutela crea incentivos perversos tanto para los pacientes como para las EPS, pues los jueces, al considerar casos individuales, no aceptan los límites de lo que puede efectivamente cubrir el POS (Daniels et al., 2009). (10) 


\section{METODOLOGIA:}

INVESTIGACIÓN HISTÓRICA. Este tipo de investigación busca reconstruir el pasado de la manera más objetiva y exacta posible, para lo cual de manera sistemática recolecta, evalúa, verifica y sintetiza evidencias que permitan obtener conclusiones válidas, a menudo derivadas de hipótesis.(1)

\section{MÉTODOS Y SUBMÉTODOS DE ESTUDIO}

El método de investigación histórica es el analítico-sintético. Es indispensable que en el estudio de las cuestiones históricas se analicen los sucesos descomponiéndolos en todas sus partes para conocer sus posibles raíces económicas, sociales, políticas, religiosas o etnográficas y partiendo de este análisis llevar a cabo la síntesis que reconstruya y explique el hecho histórico.

El método analítico es el heurístico, palabra que proviene del término griego heurisko que quiere decir yo busco, descubro y que es el método que se usa para encontrar lo nuevo, lo que se desconoce.

El método de síntesis es el hermenéutico, palabra que proviene del término griego hermeneuo, que quiere decir yo explico y que consiste en el arte y teoría de la interpretación, que tiene como fin aclarar el sentido del texto partiendo de sus bases objetivas (significaciones gramaticales de los vocablos y sus variaciones históricamente condicionadas) y subjetivas (propósitos de los autores). La investigación histórica también es deductiva-inductiva. Deducción, palabra que proviene del latín deductio, que

quiere decir sacar consecuencias de un principio, proposición o supuesto, se emplea para nombrar al método de razonamiento que lleva a la conclusión de lo general a lo particular. es muy importante conocer los hechos particulares para alcanzar las conclusiones más reales en los resultados de la investigación histórica.(2).

Por lo tanto el método de investigación histórica debe ir de lo general a lo particular, pero debe ser completado de lo particular a lo general (2) 


\section{RESULTADOS:}

Línea de tiempo de la normatividad para el trámite de recobros por tecnologías no pos por CTC y Fallos de Tutela. A lo largo del tiempo la normatividad ha cambiado, se implementado resoluciones, acuerdos, decretos, circulares, notas externas con el objetivo reglamentar el Procedimiento tramite de pago recobros Medicamento No Pos y Fallos de Tutela.

\section{MARCO LEGAL GENERAL}

\section{NORMATIVIDAD Y OTROS DOCUMENTOS EXTERNOS (5)}

\begin{tabular}{|c|c|}
\hline No. LEY & ASUNTOS \\
\hline Ley 100 de 1993 & $\begin{array}{l}\text { Por la cual se crea el Sistema de Seguridad Social en Salud y se dictan otras } \\
\text { disposiciones }\end{array}$ \\
\hline Ley 1122 de 2007 & $\begin{array}{l}\text { Por la cual se hacen algunas modificaciones en el Sistema General de } \\
\text { Seguridad Social en Salud }\end{array}$ \\
\hline Ley 1393 de 2010 & $\begin{array}{l}\text { Por la cual se definen las rentas de destinación específica para la salud, se } \\
\text { adoptan medidas para promover actividades generadoras de recursos para } \\
\text { la salud, para evitar la evasión y la elusión de aportes a la salud, se re } \\
\text { direccionan recursos al interior del sistema de salud y se dictan otras } \\
\text { disposiciones }\end{array}$ \\
\hline Ley 1438 de 2011 & $\begin{array}{l}\text { Por medio de la cual se reforma el Sistema General de Seguridad Social en } \\
\text { Salud y se dictan otras disposiciones }\end{array}$ \\
\hline Ley 1448 de 2011 & $\begin{array}{l}\text { Por la cual se dictan medidas de atención, asistencia y reparación integral a } \\
\text { las víctimas del conflicto armado interno y se dictan otras disposiciones }\end{array}$ \\
\hline Ley 1608 de 2013 & $\begin{array}{l}\text { Por medio de la cual se adoptan medidas para mejorar la liquidez y el uso de } \\
\text { algunos recursos del Sector Salud }\end{array}$ \\
\hline No. DECRETO & ASUNTO \\
\hline Decreto 1283 de 1996 & $\begin{array}{l}\text { Por el cual se reglamenta el funcionamiento del Fondo de Solidaridad y } \\
\text { Garantía del Sistema General de Seguridad Social en Salud }\end{array}$ \\
\hline Decreto 806 de 1998 & Precisa tema de atención NO POS-S (Art. 30 y 31) \\
\hline Decreto 783 de 2000 & Define Atención Inicial de Urgencias \\
\hline $\begin{array}{l}\text { Decreto Ley } 1281 \text { de } \\
2002\end{array}$ & $\begin{array}{l}\text { Por el cual se expiden las normas que regulan los flujos de caja y la } \\
\text { utilización oportuna y eficiente de los recursos del sector salud y su } \\
\text { utilización en la prestación }\end{array}$ \\
\hline Decreto 4747 de 2007 & $\begin{array}{l}\text { Por medio del cual se regulan algunos aspectos de las relaciones entre los } \\
\text { prestadores de servicios de salud y las entidades responsables del pago de } \\
\text { los servicios de salud de la población a su cargo, y se dictan otras } \\
\text { disposiciones }\end{array}$ \\
\hline Decreto 1716 de 2009 & $\begin{array}{l}\text { Por el cual se reglamenta el artículo } 13 \text { de la Ley } 1285 \text { de } 2009 \text {, el artículo } \\
75 \text { de la Ley } 446 \text { de } 1998 \text { y del Capítulo V de la Ley } 640 \text { de } 2001\end{array}$ \\
\hline Decreto Ley 019 de 2012 & $\begin{array}{l}\text { Por el cual se dictan normas para suprimir o reformar regulaciones, } \\
\text { procedimientos y trámites innecesarios existentes en la Administración } \\
\text { Pública }\end{array}$ \\
\hline Decreto 1865 de 2012 & Por el cual se reglamenta el artículo 122 del Decreto-ley 019 de 2012 \\
\hline No. RESOLUCION & ASUNTO \\
\hline Resolución 5261 de 1994 & $\begin{array}{l}\text { Manual de actividades, procedimientos e intervenciones del Plan Obligatorio } \\
\text { de Salud }\end{array}$ \\
\hline
\end{tabular}




\begin{tabular}{|c|c|}
\hline Resolución 2816 de 1998 & Atención de Urgencias- Modifica Art. 10 de la Res. 5261 de 1994 \\
\hline Resolución 3374 de 2000 & $\begin{array}{l}\text { Por la cual se reglamentan los datos básicos que deben reportar los } \\
\text { prestadores de servicios de salud y las entidades administradoras de planes } \\
\text { de beneficios sobre los servicios de salud prestados }\end{array}$ \\
\hline Resolución 4905 de 2006 & Norma técnica para interrupción voluntaria del embarazo \\
\hline Resolución 3442 de 2006 & Guías para atención de ERC y VIH-Sida \\
\hline Resolución 769 de 2008 & Norma técnica sobre Planificación familiar \\
\hline Resolución 3047 de 2008 & $\begin{array}{l}\text { Por medio de la cual se definen los formatos, mecanismos de envío, } \\
\text { procedimientos y términos a ser implementados en las relaciones entre } \\
\text { prestadores de servicios de salud y entidades responsables del pago de } \\
\text { servicios de salud, definidos en el Decreto } 4747 \text { de } 2007\end{array}$ \\
\hline Resolución 2977 de 2012 & $\begin{array}{l}\text { Por la cual se definen los términos, requisitos, formatos y períodos de } \\
\text { radicación de que trata el artículo } 5^{\circ} \text { del Decreto número } 1865 \text { de } 2012\end{array}$ \\
\hline Resolución 3778 de 2013 & $\begin{array}{l}\text { Por la cual se modifica la Resolución } 2977 \text { de } 2012 \text {, modificada por la } \\
\text { Resolución número } 4251 \text { de } 2012 \text { y se dictan otras disposiciones }\end{array}$ \\
\hline Resolución 2933 de 2006 & $\begin{array}{l}\text { Reglamenta los Comités Técnico-Científicos y se establece el procedimiento } \\
\text { de recobro ante el FOSYGA. Adiciona la fecha de -radicación de la factura } \\
\text { ante la entidad-; para contar los términos de la presentación de recobros } \\
\text { ante el FOSYGA. Codifica las causales de glosa de acuerdo con el estado de } \\
\text { auditoria. Establece el formato de objeción a la auditoria realizada (MYT-04) }\end{array}$ \\
\hline Resolución 4568 de 2005 & $\begin{array}{l}\text { Autoriza un procedimiento excepcional para los recobros presentados entre } \\
\text { el } 20 \text { de diciembre de } 2002 \text { y el } 20 \text { de noviembre de } 2004 \text { con causal única } \\
\text { de glosa: EXTEMPORÁNEIDAD. Los } 6 \text { meses de extemporaneidad se } \\
\text { cuentan a partir de la fecha de radicación de la factura en la entidad }\end{array}$ \\
\hline Resolución 3615 de 2005 & $\begin{array}{l}\text { Por la cual se adoptan los formatos para la presentación de las solicitudes de } \\
\text { recobro ante el Fondo de Solidaridad y Garantía, FOSYGA por concepto de } \\
\text { suministro de medicamentos no incluidos en el Plan Obligatorio de Salud - } \\
\text { POS y de fallos de tutela }\end{array}$ \\
\hline Resolución 2366 de 2005 & $\begin{array}{l}\text { Modifica parcialmente la Resolución } 3797 \text { de } 2004 \text {. Reglamenta lo relativo a } \\
\text { los recobros Aprobados Condicionados a pago del } 50 \% \text { del valor liquidado }\end{array}$ \\
\hline Resolución 3797 de 2004 & $\begin{array}{l}\text { Reglamenta los Comités Técnico-Científicos y establece el procedimiento de } \\
\text { recobro ante el FOSYGA. Se establecen } 4 \text { estados de resultado de auditoria: } \\
\text { Aprobado, Aprobado Condicionado, Devuelto y Rechazado. }\end{array}$ \\
\hline Resolución 2948 de 2003 & $\begin{array}{l}\text { Subrogan las Resoluciones } 5061 \text { de } 1997 \text { y } 2312 \text { de } 1998 \text {, del MSPS } \\
\text { mediante las cuales se estableció el procedimiento de recobro ante el } \\
\text { FOSYGA. Tiene vigencia para los recobros presentados hasta el } 31 \text { de enero } \\
\text { de } 2005\end{array}$ \\
\hline Resolución 2949 de 2003 & $\begin{array}{l}\text { Subrogan las Resoluciones } 5061 \text { de } 1997 \text { y } 2312 \text { de } 1998 \text {, del MSPS } \\
\text { mediante las cuales se estableció el procedimiento de recobro ante el } \\
\text { FOSYGA. Tiene vigencia para los recobros presentados hasta el } 31 \text { de enero } \\
\text { de } 2005\end{array}$ \\
\hline Resolución 3099 de 2008 & $\begin{array}{l}\text { Por la cual se reglamentan los Comités Técnico-Científicos y se establece el } \\
\text { procedimiento de recobro ante el Fondo de Solidaridad y Garantía, FOSYGA, } \\
\text { por concepto de suministro de medicamentos, servicios médicos y } \\
\text { prestaciones de salud no incluidos en el Plan Obligatorio de Salud, POS } \\
\text { autorizados por Comité Técnico Científico y por fallos de tutela }\end{array}$ \\
\hline Resolución 458 de 213 & $\begin{array}{l}\text { Que la Honorable Corte Constitucional a través de la Sentencia T-760 de } \\
2008, \text { impartió una serie de órdenes, entre otras, la adopción de las medidas } \\
\text { necesarias para la aprobación de los servicios de salud no incluidos en los } \\
\text { Planes Obligatorios de Salud (POS), distintos a medicamentos y las } \\
\text { relacionadas con el derecho a su recobro ante el Fondo de Solidaridad y } \\
\text { Garantía (Fosyga) }\end{array}$ \\
\hline Resolución 5061 de 1997 & $\begin{array}{l}\text { Por la cual se reglamentan los Comités Técnico Científicos dentro de la } \\
\text { Entidades Promotoras de Salud, Administradoras del Régimen Subsidiado e } \\
\text { Instituciones Prestadoras de Servicios de Salud }\end{array}$ \\
\hline
\end{tabular}




\begin{tabular}{|c|c|}
\hline Resolución 2312 de 1998 & $\begin{array}{l}\text { Por la cual se modifica el artículo 1o. de la Resolución } 5061 \text { de 1997, y se } \\
\text { reglamenta el recobro de medicamentos autorizados por los Comités } \\
\text { Técnico-Científicos de las EPS, ARS y entidades adaptadas. }\end{array}$ \\
\hline Resolución 3877 de 2013 & Por la cual se modifica la resolución 0458 de 2013. Solicitudes de recobro \\
\hline Resolución 5521 de 2013 & $\begin{array}{l}\text { Por la cual se define, aclara y actualiza integralmente el Plan Obligatorio de } \\
\text { Salud (POS). }\end{array}$ \\
\hline Resolución 5395 de 2013 & $\begin{array}{l}\text { Por la cual se establece el procedimiento de recobro ante el Fondo de } \\
\text { Solidaridad y Garantía (FOSYGA) y se dictan otras disposiciones }\end{array}$ \\
\hline Resolución 5926 de 2014 & Por la cual se ajusta el Anexo 01 de la Resolución 5521 de 2013 \\
\hline Resolución 5592 de 2015 & $\begin{array}{l}\text { Por la cual se define, aclara y actualiza integralmente el Plan Obligatorio de } \\
\text { Salud (POS). }\end{array}$ \\
\hline Resolución 6408 de 2016 & $\begin{array}{l}\text { Por la cual se define, aclara y actualiza integralmente el Plan Obligatorio de } \\
\text { Salud (POS). }\end{array}$ \\
\hline No. ACUERDO & ASUNTO \\
\hline $\begin{array}{l}\text { Acuerdo } 008 \text { de 1994- } \\
\text { CNSSS }\end{array}$ & $\begin{array}{l}\text { Por el cual se adopta el Plan Obligatorio de Salud para el Régimen } \\
\text { Contributivo del Sistema General de Seguridad Social en Salud }\end{array}$ \\
\hline Acuerdo 72 de 1997 & Por medio del cual se define el Plan de Beneficios del Régimen Subsidiado \\
\hline Acuerdo 74 de 1997 & Por medio del cual se adiciona el Plan de Beneficios del Régimen Subsidiado \\
\hline Acuerdo 228 de 2002 & $\begin{array}{l}\text { Por medio del cual se actualiza el Manual de Medicamentos del Plan } \\
\text { Obligatorio de Salud y se dictan otras disposiciones }\end{array}$ \\
\hline Acuerdo 226 de 2002 & $\begin{array}{l}\text { Por el cual se incluye el uso de una tecnología dentro de las prestaciones } \\
\text { que componen el Plan Obligatorio de Salud/Servicios de Radioterapia con } \\
\text { Acelerador lineal para la teleterapia con fotones }\end{array}$ \\
\hline Acuerdo 236 de 2002 & $\begin{array}{l}\text { Por el cual se modifica parcialmente el Acuerdo } 228 \text { del Consejo Nacional de } \\
\text { Seguridad Social en salud }\end{array}$ \\
\hline Acuerdos 254 de 2003 & $\begin{array}{l}\text { Por el cual se fija el valor de la Unidad de Pago por Capitación del Plan } \\
\text { Obligatorio de Salud de los Regímenes Contributivo y Subsidiado para el año } \\
2004 \text { y se dictan otras disposiciones/ Carga viral para VIH y Stent coronario } \\
\text { no recubierto (Inclusión) }\end{array}$ \\
\hline Acuerdo 259 de 2004 & $\begin{array}{l}\text { Por el cual se fija el valor de la Unidad de Pago por Capitación del Plan } \\
\text { Obligatorio de Salud de los Regímenes Contributivo y Subsidiado para el año } \\
2004 \text { y se dictan otras disposiciones/ Carga viral para VIH y Stent coronario } \\
\text { no recubierto (Inclusión) }\end{array}$ \\
\hline Acuerdo 259 de 2004 & $\begin{array}{l}\text { Por el cual se fija el valor de la Unidad de Pago por Capitación del Plan } \\
\text { Obligatorio de Salud de los Regímenes Contributivo y Subsidiado para el año } \\
2004 \text { y se dictan otras disposiciones/ Carga viral para VIH y Stent coronario } \\
\text { no recubierto (Inclusión) }\end{array}$ \\
\hline Acuerdo 260 de 2004 & $\begin{array}{l}\text { Por el cual se define el régimen de pagos compartidos y cuotas moderadoras } \\
\text { dentro del Sistema General de Seguridad Social en Salud }\end{array}$ \\
\hline Acuerdo 263 de 2004 & $\begin{array}{l}\text { Por el cual se da cumplimiento al fallo proferido por el Consejo de Estado, } \\
\text { Sala de lo Contencioso Administrativo, Sección Tercera, dentro del } \\
\text { expediente AP } 2212\end{array}$ \\
\hline Acuerdo 282 de 2004 & $\begin{array}{l}\text { Por el cual se fija el valor de la Unidad de Pago por Capitación del Plan } \\
\text { Obligatorio de Salud de los Regímenes Contributivo y Subsidiado para el año } \\
2005 \text { y se dictan otras disposiciones }\end{array}$ \\
\hline Acuerdo 289 de 2005 & $\begin{array}{l}\text { Por medio del cual se aclara la cobertura de servicios en el Plan Obligatorio } \\
\text { de Salud del Régimen Contributivo y del Régimen Subsidiado }\end{array}$ \\
\hline
\end{tabular}




\begin{tabular}{|c|c|}
\hline Acuerdo 302 de 2005 & $\begin{array}{l}\text { Por medio del cual se incluyen unas prestaciones en el Plan Obligatorio de } \\
\text { Salud del Régimen Contributivo y del Régimen Subsidiado/ Mallas para } \\
\text { hernioplastia (Inclusión) }\end{array}$ \\
\hline Acuerdo 306 de 2005 & $\begin{array}{l}\text { Por medio del cual se define el Plan Obligatorio de Salud del Régimen } \\
\text { Subsidiado. }\end{array}$ \\
\hline Acuerdo 313 de 2005 & $\begin{array}{l}\text { Por medio del cual se incluye una prestación en el Plan Obligatorio de Salud } \\
\text { del Régimen Contributivo y del Régimen Subsidiado/ Colecistectomía } \\
\text { laparoscópica (Inclusión) }\end{array}$ \\
\hline Acuerdo 336 de 2006 & $\begin{array}{l}\text { Por el cual se actualiza parcialmente el Manua de Medicamentos del Plan } \\
\text { Obligatorio de Salud, se incluyen otras prestaciones en los Planes de } \\
\text { Beneficios de los Regímenes Contributivo y Subsidiado, se modifica el valor } \\
\text { de la UPC para el } 2006 \text { y se dictan otras disposiciones. }\end{array}$ \\
\hline Acuerdo 350 de 2006 & $\begin{array}{l}\text { Por medio del cual se incluye en el Plan Obligatorio de salud del Régimen } \\
\text { Contributivo y del Régimen Subsidiado la atención para la interrupción } \\
\text { voluntaria del embarazo }\end{array}$ \\
\hline Acuerdo 368 de 2007 & $\begin{array}{l}\text { Por medio del cual se incluye un medicamento en el Manual de } \\
\text { Medicamentos y Terapéutica del Plan Obligatorio de Salud/ Inclusión } \\
\text { medicamento Lopinavir + Ritonavir en tabletas }\end{array}$ \\
\hline Acuerdo 380 de 2007 & $\begin{array}{l}\text { Por medio del cual se incluyen medicamentos anticonceptivos hormonales y } \\
\text { el condón masculino en el Plan Obligatorio de Salud del Régimen } \\
\text { Contributivo y del Régimen Subsidiado. }\end{array}$ \\
\hline $\begin{array}{l}\text { Acuerdo } 008 \text { de } 2009 \text { de } \\
\text { la CRES }\end{array}$ & $\begin{array}{l}\text { Por el cual se corrigen aclaran y actualizan integralmente los Planes } \\
\text { Obligatorios de Salud de los Regímenes Contributivo y Subsidiado }\end{array}$ \\
\hline $\begin{array}{l}\text { Acuerdo } 014 \text { de } 2010 \text { de } \\
\text { la CRES }\end{array}$ & Por el cual se corrigen algunos yerros en el Acuerdo 008 de 2009 \\
\hline $\begin{array}{l}\text { Acuerdo } 025 \text { de } 2011 \text { de } \\
\text { la CRES }\end{array}$ & $\begin{array}{l}\text { Por el cual se realizan algunas inclusiones en el Plan Obligatorio de Salud de } \\
\text { los Regímenes Contributivo y Subsidiado }\end{array}$ \\
\hline $\begin{array}{l}\text { Acuerdo } 029 \text { de } 2011 \text { de } \\
\text { CRES }\end{array}$ & $\begin{array}{l}\text { Por el cual se sustituye el Acuerdo } 028 \text { de } 2011 \text { que define, aclara y } \\
\text { actualiza integralmente el Plan Obligatorio de Salud }\end{array}$ \\
\hline No. CIRCULAR & ASUNTO \\
\hline $\begin{array}{l}\text { Circular Externa } 094 \text { de } \\
2004\end{array}$ & $\begin{array}{l}\text { Aclaración de cobertura de servicios para la Rehabilitación Pulmonar en el } \\
\text { Plan Obligatorio de Salud del Régimen Contributivo }\end{array}$ \\
\hline $\begin{array}{l}\text { Circular Externa } 010 \text { de } \\
2006\end{array}$ & $\begin{array}{l}\text { Instrucciones sobre la atención oportuna a la población, especialmente } \\
\text { cuando está en peligro la vida de los pacientes. Atención Inicial de Urgencias }\end{array}$ \\
\hline $\begin{array}{l}\text { Circular } 1 \text { de } 2012 \\
\text { CNPMSM }\end{array}$ & $\begin{array}{l}\text { Por la cual se incorporan unos medicamentos al régimen de control directo y } \\
\text { se dictan otras disposiciones }\end{array}$ \\
\hline $\begin{array}{l}\text { Circular } 3 \text { de } 2012 \\
\text { CNPMSM }\end{array}$ & Por la cual se modifica parcialmente la Circular número 01 de 2012 \\
\hline $\begin{array}{l}\text { Circular } 04 \text { de } 2012 \\
\text { CNPMSM }\end{array}$ & $\begin{array}{l}\text { Por la cual se incorporan unos medicamentos al régimen de control directo y } \\
\text { se dictan otras disposiciones. }\end{array}$ \\
\hline $\begin{array}{l}\text { Circular } 001 \text { de } 2013 \\
\text { CNPMSM }\end{array}$ & $\begin{array}{l}\text { Por la cual se aclara el sentido, interpretación y alcance del artículo } 2^{\circ} \text { de la } \\
\text { Circular No. } 01 \text { del } 14 \text { de abril de } 2010 \text { de la Comisión Nacional de } \\
\text { Medicamentos y Dispositivos Médicos }\end{array}$ \\
\hline $\begin{array}{l}\text { Circular } 002 \text { de } 2013 \\
\text { CNPMSM }\end{array}$ & $\begin{array}{l}\text { Por la cual se amplía el plazo para el desarrollo de la metodología según lo } \\
\text { establecido en el artículo } 8 \text { de la Circular } 002 \text { de } 2011 \text {, modificado por el } \\
\text { artículo } 8 \text { de la Circular } 01 \text { de } 2012 \text {. }\end{array}$ \\
\hline $\begin{array}{l}\text { Circular } 003 \text { de } 2013 \\
\text { CNPMSM }\end{array}$ & $\begin{array}{l}\text { Por la cual se establece la metodología para la aplicación del régimen de } \\
\text { control directo de precios para los medicamentos que se comercialicen en el } \\
\text { territorio nacional }\end{array}$ \\
\hline $\begin{array}{l}\text { Circular } 004 \text { de } 2013 \\
\text { CNPMSM }\end{array}$ & $\begin{array}{l}\text { Por la cual se incorporan unos medicamentos al régimen de control con } \\
\text { fundamento en la metodología de la Circular } 03 \text { de } 2013 \text { de la Comisión } \\
\text { Nacional de Precios de Medicamentos y Dispositivos Médicos y se les fija su } \\
\text { Precio Máximo de Venta en el territorio nacional }\end{array}$ \\
\hline $\begin{array}{l}\text { Circular } 005 \text { de } 2013 \\
\text { CNPMSM }\end{array}$ & Por la cual se modifica la Circular 04 de 2013 \\
\hline
\end{tabular}




\begin{tabular}{|c|c|}
\hline $\begin{array}{l}\text { Circular } 006 \text { de } 2013 \\
\text { CNPMSM }\end{array}$ & $\begin{array}{l}\text { Por la cual se incorpora al régimen de control directo el medicamento } \\
\text { KALETRA el cual contiene los principios activos Lopinavir y Ritonavir }\end{array}$ \\
\hline $\begin{array}{l}\text { Circular } 007 \text { de } 2013 \\
\text { CNPMSM }\end{array}$ & $\begin{array}{l}\text { Por la cual se incorporan unos medicamentos al régimen de control directo } \\
\text { con fundamento en la metodología de la Circular } 003 \text { de } 2013 \text { de la Comisión } \\
\text { Nacional de Precios de Medicamentos y Dispositivos Médicos y se les fija su } \\
\text { Precio máximo de venta }\end{array}$ \\
\hline $\begin{array}{l}\text { Circular } 001 \text { de } 2014 \\
\text { CNPMSM }\end{array}$ & $\begin{array}{l}\text { Por la cual se incorporan medicamentos al régimen de control directo con } \\
\text { fundamento en la metodología de la Circular } 03 \text { de } 2013 \text { de la Comisión } \\
\text { Nacional de Precios de Medicamentos y Dispositivos Médicos y se les fija su } \\
\text { precio máximo de venta, se modifica la Circular } 07 \text { de } 2013 \text { y se dictan otras } \\
\text { disposiciones }\end{array}$ \\
\hline Circular 34 de 2014 & $\begin{array}{l}\text { Auditoría Concurrente Unión Temporal FOSYGA } 2014 \text { dirigida a Entidades } \\
\text { reclamantes y reclamantes instituciones prestadoras de salud, proveedores } \\
\text { de tecnología en salud, personas jurídicas, personas naturales y demás } \\
\text { entidades involucradas en el proceso de recobros y reclamaciones ante el } \\
\text { FOSYGA. }\end{array}$ \\
\hline $\begin{array}{l}\text { Circular } 1 \text { de } 2015 \\
\text { CNPMDM }\end{array}$ & $\begin{array}{l}\text { Por la cual se interviene en los mercados de dispositivos médicos, se } \\
\text { establece un régimen de libertad vigilada para estos productos y se someten } \\
\text { uno estents coronarios a control directo. }\end{array}$ \\
\hline No. NOTA EXTERNA & ASUNTO \\
\hline 217247 de 2012 & $\begin{array}{l}\text { Conciliaciones prejudiciales e instructivas para la presentación de recobros o } \\
\text { reclamaciones en trámite de conciliación prejudicial. }\end{array}$ \\
\hline 20143320060543 & $\begin{array}{l}\text { Remisión de información reintegro de recursos por concepto de Recobros } \\
\text { por Prestaciones en salud NO POS o reclamaciones ECAT - Resolución } \\
3361 \text { de } 2013 \text {. }\end{array}$ \\
\hline 201433200014303 & $\begin{array}{l}\text { Resolución } 5395 \text { de } 2013 \text { Formatos y anexos técnicos para el proceso de } \\
\text { verificación, control y pago de las solicitudes de recobro. }\end{array}$ \\
\hline 201433200214183 & $\begin{array}{l}\text { Pre radicación de solicitudes de recobros con excepciones de validación de } \\
\text { BDUA. }\end{array}$ \\
\hline 201433200296233 & $\begin{array}{l}\text { Período de radicación de divergencias recurrentes exclusiones del POS y } \\
\text { Prestaciones No Financiadas con Recursos del SGSSS. }\end{array}$ \\
\hline 201433200296573 & Período de radicación de divergencias recurrentes. \\
\hline 201433200325243 & Período de radicación de divergencias recurrentes \\
\hline 201433200208153 & $\begin{array}{l}\text { Conciliación de etapas de pre radicación y radicación del proceso ordinario } \\
\text { (MYT 01-02) de Recobros }\end{array}$ \\
\hline 201433200179423 & Precisiones Resolución 5395 de 2013 \\
\hline 201433200170103 & Validaciones excepcionales BDUA radicación mes de julio de 2014 \\
\hline 201433200152233 & $\begin{array}{l}\text { Adopción del anexo técnico de Comparadores Administrativos para } \\
\text { medicamentos no incluidos en el Plan de Beneficios }\end{array}$ \\
\hline 201433100142683 & Orden médica en recobros originados en tutelas \\
\hline 201433210469851 & Ajuste estructura de datos para presentación económicas al FOSYGA. \\
\hline 201433200207053 & $\begin{array}{l}\text { Período de Aplicación Nota Externa MYT04 } 201433200190093 \text { del } 1 \text { de } \\
\text { agosto de } 2014 .\end{array}$ \\
\hline 201433200190093 & $\begin{array}{l}\text { Formatos para la presentación de objeción a los resultados de Auditoría } \\
\text { integral - Art. } 31 \text { de la Resolución } 5395 \text {. }\end{array}$ \\
\hline 201433200100153 & Divergencias recurrentes \\
\hline 201433200083073 & Periodo de radicación de divergencias recurrentes. \\
\hline 201433200140123 & Período de radicación divergencias recurrentes \\
\hline 201433200296523 & $\begin{array}{l}\text { Lineamientos y criterios técnicos respecto a exclusiones del POS y } \\
\text { prestaciones que no pueden ser financiadas con recursos del Sistema } \\
\text { General de Seguridad Social en Salud (SGSSS). }\end{array}$ \\
\hline 201533200002583 & Giro previo divergencias recurrentes Resolución 5648 de 2014. \\
\hline
\end{tabular}




\begin{tabular}{|c|c|c|}
\hline $\begin{array}{l}\text { No. RADICADO } \\
\text { MSPS }\end{array}$ & ASUNTO & $\begin{array}{l}\text { Fecha del } \\
\text { Documento }\end{array}$ \\
\hline $12100-212$ & $\begin{array}{l}\text { Términos de presentación de recobros Resolución } 2933 \\
\text { de } 2006\end{array}$ & $29 / 01 / 2007$ \\
\hline $12100-5197$ & $\begin{array}{l}\text { Tratamiento contable procedimiento recobros y } \\
\text { reclamaciones - Contaduría General de la Nación }\end{array}$ & $16 / 09 / 2008$ \\
\hline 7650 & $\begin{array}{l}\text { Respecto del POS para el factor Recombinante con } \\
\text { sacarosa (Kogenate F5) POS O NO POS }\end{array}$ & $26 / 12 / 2008$ \\
\hline 3377 & Validaciones al proceso de recobros y reclamaciones & $13 / 07 / 2009$ \\
\hline $12100-5820$ & $\begin{array}{l}\text { Cumplimiento de fallos de tutela en relación con el } \\
\text { régimen subsidiado }\end{array}$ & $\begin{array}{l}\text { Cumplimiento de fallos } \\
\text { de tutela en relación } \\
\text { con el régimen } \\
\text { subsidiado }\end{array}$ \\
\hline $12100-5836$ & $\begin{array}{l}\text { Aplicación de la extensión de competencias del Comité } \\
\text { Técnico Científico en cumplimiento de la sentencia C-463 } \\
\text { DE } 2008\end{array}$ & $23 / 11 / 2009$ \\
\hline 199824 & $\begin{array}{l}\text { Autorización de servicios en Salud por CTC } \\
\text { expresamente excluidos del POS }\end{array}$ & $15 / 07 / 2010$ \\
\hline 4689 & Aplicación de la Resolución 4377 de 2010 & $06 / 01 / 2011$ \\
\hline 8457 & Aclaraciones códigos CUM & $13 / 01 / 2011$ \\
\hline 2470 & $\begin{array}{l}\text { Remisión de información de recobros incautados por la } \\
\text { Fiscalía General de la Nación }\end{array}$ & $10 / 01 / 2012$ \\
\hline 11931 & $\begin{array}{l}\text { Alerta por retiro del producto Bevacizumab/Avastin en la } \\
\text { indicación del cáncer de mama }\end{array}$ & $25 / 01 / 2012$ \\
\hline 14370 & Licencias de importación Eculizumab & $27 / 01 / 2012$ \\
\hline 22064 & $\begin{array}{l}\text { Uso por fuera de la indicación aprobada (uso off label) del } \\
\text { producto Bevacizumab/Avastin en oftalmología }\end{array}$ & $07 / 02 / 2012$ \\
\hline 21177 & Licencias de importación Eculizumab & 07/02/2012 \\
\hline $3320-168828$ & $\begin{array}{l}\text { Criterio de auditoría respecto de la diferencia entre medio } \\
\text { físico y medio magnético de medicamentos facturados y } \\
\text { recobrados }\end{array}$ & $06 / 08 / 2012$ \\
\hline 196180 & $\begin{array}{l}\text { Validaciones proceso de auditoría-los recobros radicados } \\
\text { deben ser cruzados con las bases de datos indicadas. }\end{array}$ & 06/09/2012 \\
\hline 201333200341901 & $\begin{array}{l}\text { Concepto relacionado con la cobertura del POS respecto } \\
\text { del procedimiento de Ecocardiograma con Stress } \\
\text { Farmacológico }\end{array}$ & $21 / 03 / 2013$ \\
\hline 201333200398591 & $\begin{array}{l}\text { Criterios de auditoría aplicables a recobros radicados a } \\
\text { partir de marzo de } 2013\end{array}$ & $05 / 04 / 2013$ \\
\hline 201333210791301 & Interpretación Resolución 3086 de 2012 & $19 / 06 / 2013$ \\
\hline 201331100159883 & Concepto Gadolinio medio de contraste & $25 / 06 / 2013$ \\
\hline 201333200969491 & Cobertura del Plan Obligatorio de Salud del Stent & $25 / 07 / 2013$ \\
\hline 201333200969491 & $\begin{array}{l}\text { Consolidación de conceptos relacionados con la } \\
\text { cobertura del POS }\end{array}$ & $12 / 08 / 2013$ \\
\hline 201333201336521 & $\begin{array}{l}\text { Actividades, plazos y responsables en el trámite de } \\
\text { solicitudes de recobros presentadas ante el FOSYGA }\end{array}$ & $02 / 10 / 2013$ \\
\hline 201331100323903 & Conceptos respecto de la cobertura del POS & $19 / 11 / 2013$ \\
\hline 201331100324063 & Nomenclatura SOD Integralidad NO POS & $19 / 11 / 2013$ \\
\hline 201333201580941 & Concepto SOD e integralidad del NO POS & $20 / 11 / 2013$ \\
\hline 201331100368393 & Concepto cobertura de Prótesis oculares & $30 / 12 / 2013$ \\
\hline 201431100014523 & $\begin{array}{l}\text { Concepto Ecocardiograma con Stress con prueba de } \\
\text { Esfuerzo o con Prueba Farmacológica }\end{array}$ & $21 / 01 / 2014$ \\
\hline 201431100014453 & $\begin{array}{l}\text { Respuesta Solicitud Divergencias recurrentes Coomeva } \\
\text { EPS S.A }\end{array}$ & $21 / 01 / 2014$ \\
\hline 201431100032053 & Divergencias recurrentes coberturas & $21 / 01 / 2014$ \\
\hline
\end{tabular}


\begin{tabular}{|l|l|}
\hline 201431100070803 & Divergencias recurrentes coberturas
\end{tabular}

$26 / 03 / 2014$

\begin{tabular}{|l|l}
\hline 201431100107013 & Cobertura del POS para DIPEPTIVEN
\end{tabular}

$09 / 05 / 2014$

\section{SENTENCIAS}

No. Sentencia

AÑO

Sentencia SU-480

Sentencia C-510

Sentencia C-463

Sentencia T-760

Sentencia T-160

1997

2004

2008

2008

2014 


\section{DISCUSION}

Según lo indicó la Superintendencia Nacional de Salud (2012) en el informe de auditoría sobre los recobros al Fosyga por tecnologías no pos dentro del sistema de salud se expresa en dos funciones básicas:

1. Asegurar el acceso a los servicios de salud no pos por parte de los usuarios, en situaciones no previstas dentro del orden cotidiano del sistema, eliminando las barreras de acceso a los mismos, principalmente aquellas barreras de índole económica o relacionadas con la presencia de intereses ilegítimos, ordenando la prestación de los servicios y su pago de manera inmediata, dando a las EAPB la posibilidad de recobrarlos con cargo al Fosyga.

Pudo la Superintendencia demostrar, con resultados muy parecidos a los analizados en el capítulo anterior, que el cumplimiento global de los criterios evaluados en la auditoría por parte de las 20 EPAB en su conjunto asciende al $69 \%$, siendo de $81 \%$ para el módulo que evalúa los aspectos estructurales y de procesos sobre la conformación, integrantes y reuniones del CTC, y más grave aún, cumplimiento del $66 \%$ para el módulo que se centra en los resultados del CTC, expresados en sus actas y recobros. Según la Superintendencia, es de especial preocupación lo siguiente:

Existen varias amenazas para el cumplimiento de estos objetivos al interior de las EAPB. Los aspectos que mostraron un nivel de riesgo más crítico fueron el cumplimiento de los requisitos generales de información para el recobro de los servicios prestados fuera del POS (54\% de cumplimiento), el cumplimiento de los requisitos especiales de reporte de información para el recobro de casos aprobados por CTC (72\%), y el cumplimiento de los requisitos especiales de reporte de información para el recobro de casos aprobados mediante tutela (50\%). Estos tres aspectos son particularmente serios para el sistema, pues no permiten tener una visión informada de la magnitud de los costos generados por CTC, y los tipos de procedimientos y diagnósticos que generan mayor peso sobre la carga económica del sistema (Colombia. Superintendencia Nacional de Salud, 2012). (27). 
El incumplimiento de procesos, procedimientos y actividades respecto del funcionamiento de los Comités Técnico Científicos es grave, en tanto que su impacto impide el acceso de la población a los servicios de salud, demostrado con la demora en la oportunidad de acceso a los mismos. Los impactos directos e indirectos sobre los costos para el Sistema General de Seguridad también merman la capacidad de respuesta, en tanto que se pudo demostrar con el número de glosas, que se están recobrando medicamentos o servicios incluidos en el Plan Obligatorio de Salud. (28).

Sobre este último asunto en particular, la Defensoría del Pueblo (2012) señaló que de las 105.947 tutelas interpuestas invocando el derecho a la salud en $2011,67.81 \%$ de lo solicitado a las EPS estaba incluido en el Plan Obligatorio de Salud (POS), es decir, los pacientes tuvieron que interponer una tutela para reclamar servicios, procedimientos 0 medicamentos a los que tenían legítimo derecho y les fueron negados.

Sin embargo, no hay que dejar de reconocer que las medidas que ha adoptado el Ministerio de Salud desde 2010 relacionadas con valore máximos de reconocimiento de medicamentos y procedimientos para el recobro ante el Fosyga por parte de las EPS, ha disminuido notoriamente el porcentaje que con cargo al presupuesto de la Nación se desembolsa para cubrir servicios que están por fuera del plan de beneficios y que son requeridos por los usuarios del sistema con argumento de necesidad.

Mientras en el 2010 se pagaban en promedio $\$ 220$ mil millones mensuales por recobros, en 2011 la cifra no superó los \$160 mil millones mensuales. En el mes de mayo de 2011 se quebró por primera vez la tendencia ascendente de recobros y disminuyeron cerca al 22 por ciento (Colombia. Ministerio de Salud y Protección Social, 2011). (22). Lo que significa que se han hecho esfuerzos significativos tendientes al equilibrio financiero del sistema. Por otra parte, un sondeo de mercado realizado por el Ministerio, sobre los efectos de las medidas de los valores máximos de reconocimiento de medicamentos, mostró que la disminución en los costos de los medicamentos es de entre 20 y 25 por ciento, que está en el rango de los ahorros calculados. Ponerle topes a los valores de 
reconocimiento de los medicamentos, que son cerca del 88 por ciento de los valores recobrados, es otra de las medidas que se está reflejando en la disminución.

Según un estudio realizado por Fedesarrollo (Núñez, Zapata, Castañeda, Fonseca, \& Ramírez, 2012), aunque hubo disminución de recobros en 2011, la situación no mejora en la proporción esperada, de ahí que precisen lo siguiente:

Para el 2011 este monto se redujo, aunque la disminución presentada fue mucho menor a las que esperaba el gobierno con las medidas tomadas para su control. Los gastos por esta vía han sido objeto de cuestionamiento de diverso orden: frente a cierto tipo de prestaciones hay profundas dudas sobre su pertinencia, dado que se concentra en un número muy bajo de la población afiliada, en algunos atendidos con medicamentos de muy alto costo e impacto marginal en el tiempo y calidad de vida sobre la salud de los pacientes. Puntualmente, vale la pena hacer énfasis en el caso de los medicamentos biotecnológicos, cuyo gasto tiene un impacto considerable sobre el valor de los recobros. Por un lado, el alto nivel de precios guarda estrecha relación con la competencia en mercado de estos medicamentos, ya que en Colombia en estos momentos hay un fuerte dominio del mercado por parte de los innovadores y muy baja participación de los genéricos. Aunque no es el caso entrar en la discusión sobre las ventajas y desventajas de mantener cerrado o abierto este mercado, sí debe quedar claro que los países donde se ha permitido una mayor competencia, los precios de los medicamentos han disminuido sensiblemente, con un impacto positivo sobre las finanzas de la salud (Núñez et al., 2012). (25). 


\section{CONCLUSIONES Y RECOMENDACIONES}

A partir del 2010, se adoptaron medidas encaminadas para hacer mas eficiente el uso de los recursos, actualizando y precisando el contenido del plan obligatorio de salud POS, y efectuando el control sobre precios de medicamentos y mejorar el flujo de recursos precisando de lineamientos y criterios de auditoria que se aplican a los recobros presentados, optimizando el procedimiento para la verificación, control y pago de las solicitudes de recobros y adoptando los mecanismos de control para asegurar la transparencia en la administración de recursos. (14).

La definición explícita del plan de beneficios con participación de todos los actores del sistema de salud es fundamental para la legitimación del mismo. Este proceso de discusión, que además deberá apelar a criterios de costo-efectividad, tendrá que hacer consiente a los usuarios que aún en países con mejor situación económica que Colombia no es posible ofrecer un plan de beneficios que lo incluya todo (Giedion \& Pulido, 2007).(26). Sin embargo, cuando ya se tiene abierta la posibilidad de acceder a servicios que se encuentran por fuera del plan de beneficios, inclusive y más aún, por vía judicial, es necesario que el sistema de salud establezca una instancia que con criterio técnico apruebe o desapruebe la prescripción médica en el menor tiempo posible y sin poner en peligro la salud de los usuarios, aumentando el número de trámites o haciendo más difícil el acceso al servicio. Se espera que con la actualización del POS, y sobre todo con la entrada en vigencia de la Resolución 5521 del 27 de diciembre de 2013 (Colombia. Ministerio de Salud y Protección Social, 2013), por la cual se define, aclara y actualiza integralmente el Plan Obligatorio de Salud (POS), se haya superado el problema de la indefinición, y en consecuencia disminuya el monto de recobros, dada la disminución, también de zonas grises o de incertidumbre, que favorecían el recobro de servicios incluidos. El alto número de recobros y de acciones de tutela para solicitar tecnologías excluidas del plan de beneficios confirman que hasta 2011 aún existía una amplia zona gris que no permitía distinguir con claridad lo incluido de lo excluido. Conforme a la evidencia internacional, se sugiere al Ministerio de Salud, trabaje en la elaboración de guías clínicas, ojalá en todas las patologías excluidas e incluidas en el POS, de tal forma 
que aparte de servir como herramienta de priorización del gasto con impacto positivo en la salud, sirva como herramienta que integre las patologías, servicios, medicamentos y tratamientos que se enuncian a manera de "lista de mercado". Es claro que deben ser varios los criterios a observarse para la inclusión o exclusión del POS, inclusive para el reconocimiento cuando están por fuera. Reconocer servicios altamente recobrados como los oncológicos pero pocas veces solicitados, resultaría, desde la óptica del bien común, una lesión a los derechos de las mayorías en favor de intereses particulares; pero desde una visión de derechos, negarlos significaría atentar contra la salud, la vida y la integridad de quien los reclama.

En todo caso, y aunque se adopte un enfoque de derechos o un enfoque de mercado para decidir qué servicios de salud autorizar, deberá prevalecer un debido proceso que responda con criterios técnicos y científicos a las demandas en salud, y que además sea impermeable a los ofrecimientos de actores del sistema con más poder y con intereses particulares que menoscaban el bien común.

De acuerdo con el informe, los recobros se dan por la falta de definición sobre si un procedimiento o medicamento está en el POS por las múltiples presentaciones que pueden llegar a tener y por la falta de una actualización periódica del plan que se ajuste "al perfil de la salud de la población colombiana, situación que lleva a vacíos legales y a aprovechamientos de diversos actores del Sistema".

Entre los factores que permitieron "recobros oportunistas", está además la modificación de las presentaciones y concentraciones de los medicamentos y hasta el hecho que algunos procedimientos están en el POS para ciertas edades y para otras no.

Por otro lado, la investigación concluyó que entre el 2006 y el 2011 hubo "discrepancias significativas" en los precios de los medicamentos y procedimientos, que incluso hacían que se cobrara distinto por un mismo producto.

Ante este panorama, la Procuraduría exhortó a las diferentes instancias del Sistema de Salud, a los usuarios y a los actores judiciales para que se "trabaje por erradicar prácticas 
que pueden ser oportunistas en detrimento de los intereses comunes, y se tomen las medidas preventivas a que haya lugar para preservar la defensa del patrimonio público" Más allá de estandarizar un proceso de auditoria en recobros por tecnologías de salud no pos, es pensar que el control de la efectividad de los procesos debe ser interno y considerarse como un instrumento esencial para el sistema de salud en el recobro/cobro de las tecnologías no pos al estado, ya que de manera continua se identifican que hay cobros excesivos por algunas tecnologías de salud.

Se considera la estandarización como motor de la innovación y como incentivo para la creatividad de las personas que están al frente del proceso. Un buen estándar es aquel que es modificado por lo menos una vez cada seis meses. Esta premisa obliga a estar buscando mejores maneras de hacer las cosas con el desarrollo de las personas. 


\section{BIBLIOGRAFIA}

Cifras Financieras del Sector Salud, Direccion de Administración de Fondos de la Protección Social, recobros al FOSYGA por tecnologías en salud no incluidas en el plan de beneficios 2009-2014. Boletin bimestral No. 11 julio - agosto de 2015.

Ambito Juridico, Presentan investigación sobre impacto de recobros de medicamentos y procedimientos al Fosyga, https://www.ambitojuridico.com/.../presentan-investigacionsobre-impacto-de-recobro...

Observatorio del medicamento Colombia. Boletin informática y salud y boletín del consumidor de medicamentos. www.med-informatica.net/BIS/WebMail 03a09ago09.htm

El Abuso en los recobtros, el dolor de cabeza del fosyga, www.elcolombiano.com/.../elabuso-en-los-recobros-el-dolor-de-cabeza-del-fosyga-B...

Manual de Auditoria Integral de Recobros por Tecnologias en Salud no incluidas en el Plan de beneficios, Ministerio de Salud y Proteccion Social, Bogota mayo de 2015

Becerril-Montekio, V., Reyes, J., \& Manuel, A. (2011). Sistema de salud de Chile. Salud Pública de México, 53(Sup 2), 132-143.

Giedion, U., \& Pulido, A. (2007). Experiencia internacional en diseño y ajuste de un Plan de Beneficios: criterios, procesos e instituciones. Bogotá: Ministerio de la Protección Social.

Giedion, U. (2008). Ampliación de cobertura y sostenibilidad financiera: el caso de Colombia. San José de Costa Rica: Banco Interamericano de Desarrollo. 
Giedion, U., Panopoulou, G., \& Gómez-Fraga, S. (2009). Diseño y ajuste de los planes explícitos de beneficios: el caso de Colombia y México. Santiago de Chile: Naciones Unidas.

Daniels, N., Saloner, B., \& Gelpi, A. H. (2009). Access, cost, and financing: achieving an ethical health reform. Health Affairs (Project Hope), 28(5), 909-916. doi:10.1377/hlthaff.28.5.w909.

Colombia. Corte Constitucional. (2008b). Sentencia T-760 de 2008. Magistrado Ponente: Manuel José Cepeda Espinosa. Bogotá: Corte Constitucional.

Cubillos, L. (2013). Iniciativa regional sobre priorización, equidad y mandatos constitucionales en salud. Washington: Banco Mundial.

United States of America. Center for Medicare \& Medicaid Services. (2011). Centros de servicios de Medicare y Medicaid. Baltimore: Centers for Medicare \& Medicaid Services.

Slideshare, investigacion histórica. https://es.slideshare.net/isabelolmeda/investigacionhistorica. BVS Cuba, Conceptos y metodología de la investigación histórica. 20. Manual de Auditoria Integral de Recobros por Tecnologias en Salud no incluidas en el Plan de Beneficios, Ministerio de Salud y Proteccion Social, Bogota mayo de 2015

Colombia. Congreso de la República. (1993). Ley 100 de 1993: por la cual se crea el sistema de seguridad social integral y se dictan otras disposiciones. Bogotá: Diario Oficial.

Colombia. Congreso de la República. (2007). Ley 1122 de 2007: Por la cual se hacen algunas modificaciones en el Sistema General de Seguridad Social en Salud y se dictan otras disposiciones. Bogotá: Diario Oficial.

Colombia. Corte Constitucional. (2006). Sentencia T-662 de 2006. Magistrado Ponente: Rodrigo Escobar Gil. Bogotá: Corte Constitucional. 52 
Colombia. Corte Constitucional. (2009). Sentencia T-438 de 2009. Magistrado Ponente: Gabriel Eduardo Mendoza Martelo. Bogotá: Corte Constitucional.

Colombia. Congreso de la República. (2011). Ley 1438 de 2011: Por medio de la cual se reforma el Sistema General de Seguridad Social en Salud y se dictan otras disposiciones. Bogotá: Diario Oficial.

Castrillón, J. (2009). Resultados del taller de consenso de los criterios para la priorización de condiciones de salud para la realización de guía integral y la estimación de sus ponderadores. Bogotá: Ministerio de la Protección Social.

Ariza, J. F., Giedion, U., \& Pulido, A. (2007). Hitos centrales en el diseño, implementación y ajuste del POS. Bogotá: Ministerio de la Protección Social.

Colombia. Ministerio de la Protección Social. (2011). Resolución 3470 del 18 de agosto de 2011: por la cual se establecen valores máximos para el reconocimiento y pago de recobros por medicamentos no incluidos en los planes de beneficios con cargo a los recursos del Fondo de Solidaridad y Garantía - FOSYGA. Bogotá: Diario Oficial.

Giedion, U., Panopoulou, G., \& Gómez-Fraga, S. (2009). Diseño y ajuste de los planes explícitos de beneficios: el caso de Colombia y México. Santiago de Chile: Naciones Unidas.

Colombia. Ministerio de Salud y Protección Social. (2013). Resolución 5521 de 2013: Por la cual se define, aclara y actualiza integralmente el Plan Obligatorio de Salud (POS). Bogotá: Diario Oficial.

Núñez, J., Zapata, J. G., Castañeda, C., Fonseca, M., \& Ramírez, J. (2012). La sostenibilidad financiera del sistema de salud colombiano: dinámica del gasto y principales retos de cara al futuro. Bogotá: Fedesarrollo. 
Giedion, U., \& Pulido, A. (2007). Experiencia internacional en diseño y ajuste de un Plan de Beneficios: criterios, procesos e instituciones. Bogotá: Ministerio de la Protección Social.

Colombia. Superintendencia Nacional de Salud. (2012). Informe actuaciones de inspección, vigilancia y control: procedimiento Comité Técnico Científico años 2010-2011. Bogotá: Supersalud.

Colombia. Defensoría del Pueblo. (2012). La Tutela y el derecho a la salud 2011: 20 años del uso efectivo de la tutela, 1992-2011. Bogotá: Defensoría del Pueblo.

Castrillón, J. (2009). Resultados del taller de consenso de los criterios para la priorización de condiciones de salud para la realización de guía integral y la estimación de sus ponderadores. Bogotá: Ministerio de la Protección Social.

Colombia. Corte Constitucional. (2002). Sentencia T-344 de 2002. Magistrado ponente: Manuel José Cepeda Espinosa. Bogotá: Corte Constitucional.

Colombia. Corte Constitucional. (2008a). Sentencia C-463 de 2008. Magistrado Ponente: Humberto Antonio Sierra Porto. Bogotá: Corte Constitucional.

Colombia. Corte Constitucional. (2008b). Sentencia T-760 de 2008. Magistrado Ponente: Manuel José Cepeda Espinosa. Bogotá: Corte Constitucional.

Colombia. Ministerio de la Protección Social. (2008a). Resolución 3099 de 2008: por la cual se reglamentan los Comités Técnico - Científicos y se establece el procedimiento de recobro ante el Fondo de Solidaridad y Garantía, Fosyga, por concepto de suministro de medicamentos, servicios médicos y prestaciones. Bogotá: Diario Oficial. 
